\title{
PERAN MEDIA CETAK LOKAL DALAM KOMUNIKASI BENCANA SEBAGAI PENDUKUNG MANAJEMEN BENCANA
}

\author{
Muhammad Annapisa \\ Pusat Kajian Pembangunan Berkelanjutan
}

\begin{abstract}
Abstrak
Upaya manajemen bencana alam yang terjadi di Indonesia saat ini memerlukan dukungan dari media massa dalam melakukan komunikasi kepada masyarakat. Degradasi lingkungan dan global warming menyebabkan wilayah Indonesia menjadi rawan bencana. Informasi mengenai situasi pra bencana, saat kejadian, dan pasca bencana menentukan terbentuknya keamanan dan kemampuan warga menghadapi bencana. Media cetak lokal dapat berperan sebagai early warning system dan melakukan edukasi bagi masyarakat. Konvergensi media saat ini memberikan kemudahan bagi masyarakat untuk mengakses informasi mengenai bencana penting yang dapat mendukung efisiensi manajemen bencana. Kajian ini bertujuan untuk memberikan gambaran mengenai pengemasan informasi bencana di media massa. Konsep yang digunakan sebagai dasar kajian adalah jurnalisme bencana, komunikasi risiko bencana dan manajemen bencana. Metode penelitian menggunakan studi literatur dan analisis teks framing pada media cetak yang memberitakan berita bencana, dengan pilihan kasus pada pemberitaan oleh harian pagi Rakyat Riau. Hasil dari kajian ini menunjukkan bahwa peran komunikasi bencana menentukan keberhasilan pemerintah untuk memberikan informasi bagi keamanan masyarakat dan mengatasi bencana yang terjadi. Kajian ini memberikan kontribusi bahwa optimalisasi komunikasi bencana secara terpadu penting dalam manajemen bencana, sinergi dengan pelibatan media massa dan masyarakat dalam distribusi informasi melalui pemanfaatan media.
\end{abstract}

Kata kunci: peran media cetak, komunikasi risiko bencana, manajemen bencana, framing media 


\section{PENDAHULUAN}

Peristiwa banjir di Riau merupakan bencana tahunan yang datang setiap musim hujan. Sejak awal Desember 2009 lalu tingginya curah hujan menyebabkan sejumlah sungai besar di Riau meluap dan meyebabkan banjir. Sebagai sebuah peristiwa, banjir mempunyai nilai berita. Ada beberapa nilai yang harus dipenuhi oleh suatu peristiwa untuk rnenjadi sebuah berita. Nilai-nilai tersebut antara lain nilai proximity, yaitu peristiwa yang mengandung unsur kedekatan dengan pembaca, akan menarik perhatian, baik secara geografis maupun emosional. Jika pembaca mengetahui tempat dimana suatu peristiwa terjadi, mereka akan cenderung memiliki keterikatan peristiwa tersebut dengan orang yang terlibat di dalamnya. Peristiwa banjir juga memiliki nilai human interest, yaitu kejadian yang terkandung unsur yang menarik empati, simpati, atau menggugah perasaan khalayak yang membacanya (Kusumaninggrat, 2005:64).

Masyarakat memerlukan edukasi mengenai bencana dan pencegahannya, media massa dapat menjadi medium dalam mendukung edukasi ini. Pemahaman mengenai bencana alam dan dampaknya, perlu diinformasikan kepada masyarakat. Sebagaimana dalam Undang-undang Nomor 24 Tahun 2007 Tentang Penanggulangan Bencana, definisi bencana adalah peristiwa atau rangkaian peristiwa yang mengancam dan mengganggu kehidupan dan penghidupan masyarakat yang disebabkan oleh faktor alam dan faktor manusia sehingga mengakibatkan timbulnya korban jiwa, kerusakan lingkungan, kerugian harta benda dan dampak psikologis. Sedangkan bencana alam adalah bencana yang diakibatkan oleh peristiwa atau serangkaian peristiwa yang disebabkan oleh alam antara lain berupa gempa bumi, tsunami, gunung meletus, banjir, kekeringan, angin topan dan tanah longsor. Pada tahun 2009, sejak bulan November sampai Desember 2009 mengalami bencana banjir, sebagaimana pada Gambar 1.

Informasi untuk memberikan peringatan dini kepada masyarakat sangat dibutuhkan masyarakat agar dapat beraktivitas dengan aman pada suatu daerah dan memiliki informasi untuk mempersiapkan aktivitas dalam menghadapi bencana. Media massa dapat memberikan informasi mengenai lokasi daerah rawan bencana di Riau, 
meningkatkan pengetahuan, sikap dan keterampilan masyarakat dan pemerintah dalam menghadapi bencana, memahami gejala-gejala awal dan mitigasinya, mempertimbangkan potensi bencana, dan memahami sumber bencana. Maka komunikasi sangat diperlukan dalam proses pembentukan kesiapan masyarakat dalam menghadapi bencana, baik bencana alam maupun bencana akibat manusia.

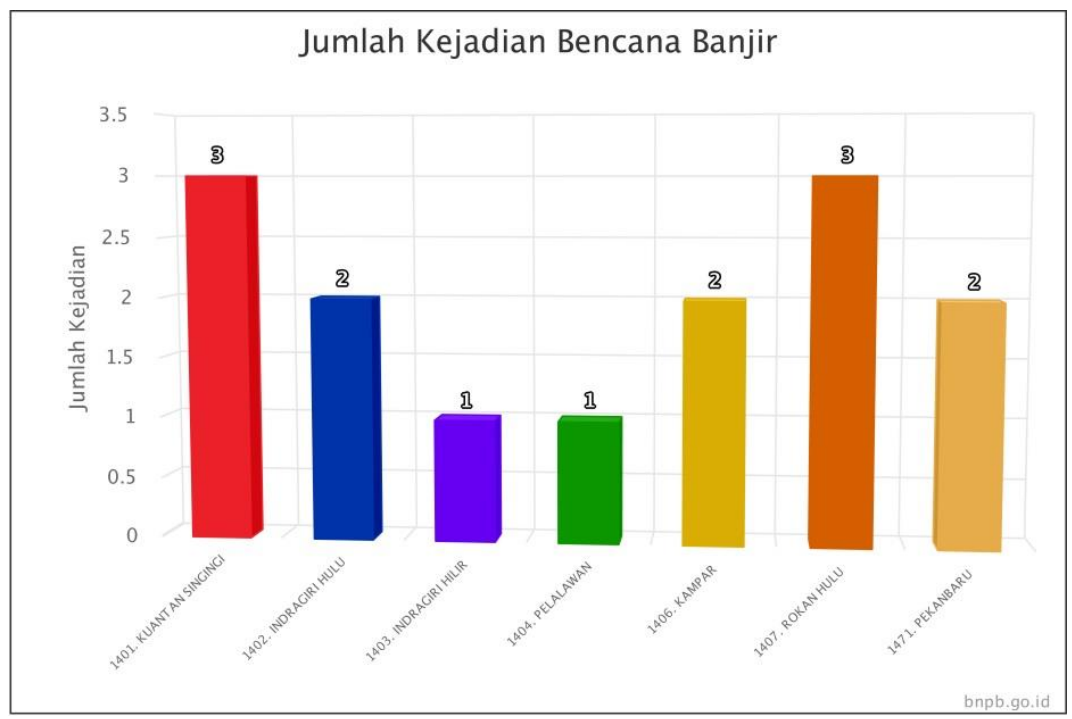

Sumber : (http://dibi.bnpb.go.id)

Hal utama berkaitan dengan peran media massa dalam penyajian berita bencana, dikarenakan bencana yang terjadi biasanya menciptakan situasi dan dampak yang tidak pasti (uncertainty). Masyarakat akan berusaha mencari informasi mengenai situasi dan komunikasi amat diperlukan untuk mengurangi ketidakpastian. Selain itu, bagi pihak media, bencana merupakan sebuah peristiwa besar yang tidak bisa dilewatkan karena bencana memiliki daya tarik yang luar biasa, tanpa harus direkayasa (Putra, 2006).

Persoalan menjadi lain manakala perhatian pers hanya terfokus terhadap persoalan tertentu selama berhari-hari. Biasanya yang mendapat tempat di halaman utama adalah berita politik, ekonomi, dan hukum. Sebab, apa yang menurut pers merupakan persoalan yang penting mendapat perhatian publik di surat kabar, belum tentu sama 
dengan apa yang juga menurut publik itu sendiri penting untuk diperhatikan.

Berangkat dari fenomena tersebut, penulis tertarik untuk melakukan penelitian terhadap peran media lokal dal hal ini harian pagi Rakyat Riau sebagai saluran dalam proses komunikasi risiko bencana dalam tahapan manajemen bencana.

\section{METODE PENELITIAN}

Penelitian ini menggunakan pendekatan kualitatif dengan sifat penelitian deskriptif yang dilakukan pada kajian level teks dengan teknik pengumpulan data melalui studi dokumentasi dengan pengumpulan teks berita yang dipilih secara purposif. Kriteria teks yang dijadikan unit analisis adalah pemberitaan mengenai banjir di Riau pada harian pagi Rakyat Riau selama bulan Desember 2009.

Untuk teknik analisis teks yang digunakan pada kajian ini adalah analisis framing dari pemikiran Zhongdang Pan dan Gerald M. Kosicki. Melalui model analisis tersebut berita akan dibingkai melalui perangkat framing yang dibagi dalam empat struktur besar, yaitu Sintaksis, Skrip, Tematik, dan Retoris (Sobur, 2009:175). Seperti terlihat di tabel :

\begin{tabular}{|l|r|l|}
\hline STRUKTUR & $\begin{array}{l}\text { PERANGKAT } \\
\text { FRAMING }\end{array}$ & $\begin{array}{l}\text { UNIT YANG } \\
\text { DIAMATI }\end{array}$ \\
\hline $\begin{array}{l}\text { Sintaksis } \\
\text { Cara wartawan } \\
\text { menyusun fakta }\end{array}$ & 1. Skema berita & $\begin{array}{l}\text { Headline, lead, latar } \\
\text { informasi, kutipan } \\
\text { sumber, pernyataan, } \\
\text { penutup }\end{array}$ \\
\hline $\begin{array}{l}\text { Skrip } \\
\text { Cara wartawan } \\
\text { mengisahkan } \\
\text { fakta }\end{array}$ & $\begin{array}{l}\text { Kelengkapan } \\
\text { berita }\end{array}$ & $5 \mathrm{~W}+1 \mathrm{H}$ \\
\hline $\begin{array}{l}\text { Tematik } \\
\text { Cara wartawan } \\
\text { menulis fakta }\end{array}$ & $\begin{array}{l}\text { 3. Detail } \\
\text { Koherensi } \\
\text { 5entuk } \\
\text { kalimat }\end{array}$ & $\begin{array}{l}\text { Paragraf, proposisi, } \\
\text { kalimat, hubungan } \\
\text { antar } \\
\text { kalimat }\end{array}$ \\
\hline
\end{tabular}




\begin{tabular}{|l|ll|l|}
\hline & 6. & Kata ganti & \\
\hline Retoris & 7. Leksikon & Kata, idiom, \\
Cara wartawan & 8. Grafis & gambar/foto, grafik \\
menekankan fakta & 9. Metafora & \\
\hline
\end{tabular}

Sumber data primer menurut Lofland dalam (Lexy J. Moleong, 2007:157) : "Sumber data utama dalam penelitian kualitatif ialah katakata dan tindakan selebihnya adalah data tambahan seperti dokumen dan lain-lain. Berkaitan dengan hal itu pada bagian ini jenis datanya dibagi kedalam kata-kata dan tindakan, sumber data tertulis, foto dan statistik".

Sumber data sekunder menurut Lexy J. Moleong (2007: 159) dikatakan bahwa: "Sumber diluar kata dan tindakan merupakan sumber kedua. Dilihat dari segi sumber data, bahan tambahan yang berasal dari sumber tertulis dapat dibagi atas sumber buku dan majalah ilmiah, sumber dari arsip, dokumen pribadi, dan dokumen resmi”.

\section{HASIL PENELITIAN}

Di bawah ini adalah hasil penelitian analisis framing terhadap beberapa berita tentang banjir di Riau pada Harian Rakyat Riau selama bulan Desember 2009.

\section{Hasil analisis: Framing Rakyat Riau Edisi Senin, 7 Desember 2009}

\begin{tabular}{|l|l|}
\hline \multicolumn{1}{c}{ Struktur } & \multicolumn{1}{c|}{ Judul Berita } \\
\cline { 2 - 3 } Sintaksis & $\begin{array}{l}\text { Sejumlah Kawasan di Pekanbaru Kebanjiran } \\
\text { menganjian berita berusaha memberikan signal } \\
\text { bukan pada penanganan banjir hal ini terlihat pada } \\
\text { setiap paragraf berita. }\end{array}$ \\
\hline Skrip & $\begin{array}{l}\text { Unsur 5 W + 1 H secara manifes telah terpenuhi, } \\
\text { tetapi pemilihan dan penggunaan dari kelengkapan } \\
\text { ini belum berimbang dalam kasus banjir di } \\
\text { Pekanbaru tidak ada kebijakan pemerintah dalam } \\
\text { menangani persoalan banjir. }\end{array}$ \\
\hline Tematik & $\begin{array}{l}\text { Tematik yang dibangun dalam teks berita ini untuk } \\
\text { menjelaskan kronologis sebab terjadinya banjir. }\end{array}$ \\
\hline
\end{tabular}


Retoris

Dalam teks berita ini, Harian Rakyat Riau tidak menyajikan seperti grafis ataupun foto.

Hasil analisis: Framing Rakyat Riau Edisi Rabu, 9 Desember 2009

\begin{tabular}{|l|l|}
\hline \multicolumn{1}{|c|}{$\begin{array}{l}\text { Struktur } \\
\text { Framing }\end{array}$} & \multicolumn{1}{|c|}{ Judul Berita } \\
\cline { 2 - 3 } Sintaksis & $\begin{array}{l}\text { Dalam teks berita ini Harian Pagi Rakyat Riau } \\
\text { memberi informasi tentang rencana pemerintah } \\
\text { menyiapkan lahan relokasi. Upaya pemerintah } \\
\text { merelokasi pengungsi dan pembangunan } \\
\text { pemukiman ke wilayah lain untuk pengungsi } \\
\text { masih belum jelas. }\end{array}$ \\
\hline Skrip & $\begin{array}{l}\text { Unsur 5 W + 1 H telah terpenuhi, tetapi sebagai } \\
\text { suatu bencana serta keterkaitan dengan kebijakan } \\
\text { pemerintah dalam penanganan banjir masih belum } \\
\text { terjawab. }\end{array}$ \\
\hline Tematik & $\begin{array}{l}\text { Tematik yang dibangun dalam teks berita ini } \\
\text { membentuk kerangka piker yaitu; Kurangnya } \\
\text { kebijakan pemerintah dalam bencana banjir di } \\
\text { Rohul, pemerintah perlu memperhatikan masalah } \\
\text { relokasi bagi warga. }\end{array}$ \\
\hline Retoris & $\begin{array}{l}\text { Dalam teks berita ini, Harian Pagi Rakyat Riau } \\
\text { tidak menyajikan ornament-ornamen seperti } \\
\text { grafis ataupun foto. }\end{array}$ \\
\hline
\end{tabular}

Hasil analisis: Framing Rakyat Riau Edisi Senin, 14 Desember 2009

\begin{tabular}{|l|l|}
\hline \multicolumn{1}{|c|}{$\begin{array}{c}\text { Struktur } \\
\text { Framing }\end{array}$} & \multicolumn{1}{|c|}{ Judul Berita } \\
\cline { 2 - 2 } Sintaksis & $\begin{array}{l}\text { Korban Banjir di Palas mulai Terserang } \\
\text { Penyakit }\end{array}$ \\
\hline & $\begin{array}{l}\text { Pahaya mengenaita berusaha memberikan informasi } \\
\text { mulai terserang penyakit. Sementara obat-obatan } \\
\text { dan bahan pangan belum diberikan pemerintah } \\
\text { Kota Pekanbaru. }\end{array}$ \\
\hline
\end{tabular}




\begin{tabular}{|l|l|}
\hline Skrip & $\begin{array}{l}\text { Sebagai surat kabar berskala daerah Harian Pagi } \\
\text { Rakyat Riau memang sangat memperhatikan }\end{array}$ \\
& $\begin{array}{l}\text { Unsur } 5 \mathrm{~W}+1 \mathrm{H} \text {. pemilihan unsur-unsur } \\
\text { kelengkapan teks berita di sini mendukung tema } \\
\text { atau konstruksi darai Rakyat Riau sendiri. }\end{array}$ \\
\hline Tematik & $\begin{array}{l}\text { Secara tematis, kerangka pikir yang disuguhkan } \\
\text { oleh Harian Pagi Rakyat Riau dalam teks berita ini } \\
\text { adalah pemerintah perlu memperhatikan masalah } \\
\text { bahan pangan obat-obatan dalam penanganan } \\
\text { banjir di Palas, Pekanbaru. }\end{array}$ \\
\hline Retoris & $\begin{array}{l}\text { Dalam teks berita ini, Harian Pagi Rakyat Riau } \\
\text { tidak menyajikan ornament-ornamen seperti } \\
\text { grafis ataupun foto. }\end{array}$ \\
\hline
\end{tabular}

\section{Hasil analisis: Framing Rakyat Riau Edisi Selasa, 15 Desember 2009}

\begin{tabular}{|l|l|}
\hline \multicolumn{1}{|c|}{$\begin{array}{c}\text { Struktur } \\
\text { Framing }\end{array}$} & \multicolumn{1}{|c|}{ Judul Berita } \\
\cline { 2 - 3 } Sintaksis & $\begin{array}{l}\text { Sesuai dengan judulnya, Harian Pagi Rakyat Riau } \\
\text { melaporkan tinjauan Bupati bersama rombongan } \\
\text { dan beberapa Kepala Dinas yang terkait ke } \\
\text { sejumlah titik lokasi banjir di 4 (empat) kecamatan } \\
\text { di Kabupaten Kampar. }\end{array}$ \\
\hline Skrip & $\begin{array}{l}\text { Kelengkapan berita Harian Pagi Rakyat Riau } \\
\text { semua sudah memperhatikan Unsur 5 W + 1 H, } \\
\text { tetapi pemilihan dan penggunaan dari } \\
\text { kelengkapan teks berita ini belum berimbang } \\
\text { dalam penangganan banjir di Kampar terutama } \\
\text { dari kebijakan pemerintah yang lebih di utamakan. }\end{array}$ \\
\hline Tematik & $\begin{array}{l}\text { Tematis teks berita ini, kebijakan pemerintah } \\
\text { sudah tepat tentang solidaritas dan kepedulian } \\
\text { terhadap warga Kampar yang terkena bencana } \\
\text { banjir. }\end{array}$ \\
\hline Retoris & $\begin{array}{l}\text { Foto dalam berita ini gambar Bupati Kampar dan } \\
\text { rombongan memakai sampan meninjau lokasi } \\
\text { banjir. }\end{array}$ \\
\hline
\end{tabular}




\section{Hasil analisis: Framing Rakyat Riau Edisi Rabu, 16 Desember 2009}

\begin{tabular}{|l|l|}
\hline \multicolumn{1}{|c|}{ Struktur } & \multicolumn{1}{c|}{ Judul Berita } \\
\cline { 2 - 3 } Sintaksis & $\begin{array}{l}\text { Banjir, Jalan Desa Mulai Terputus } \\
\text { Berita memberikan signal mengenai jalan desa } \\
\text { terendam tidak bisa dilewati, warga terpaksa } \\
\text { menggunakan sampan. Ini tentunya menimbulkan } \\
\text { keprihatinan buat pernbacanya. }\end{array}$ \\
\hline Skrip & $\begin{array}{l}\text { Unsur 5 W+I H telah terpenuhi, tetapi sebagai } \\
\text { bencana banjir ada keterkaitan dengan kebijakan } \\
\text { pemerintah dalam penanganan banjir. }\end{array}$ \\
\hline Tematik & $\begin{array}{l}\text { Pada setiap paragraf berita ini Harian Rakyat Riau } \\
\text { memberikan informasi mengenai banjir di } \\
\text { kecarnatan Langgam dan Kecamatan Pangkalan } \\
\text { Kerinci yang merepresentasikan kondisi belum } \\
\text { berubah dan ketinggian } \\
\text { air Sei Ara terus bergerak naik. }\end{array}$ \\
\hline Retoris & $\begin{array}{l}\text { Rakyat Riau tidak menyajikan seperti grafis } \\
\text { ataupun foto dalam berita teks berita ini. }\end{array}$ \\
\hline
\end{tabular}

Hasil analisis: Framing Rakyat Riau Edisi Senin, 28 Desember 2009

\begin{tabular}{|l|l|}
\hline \multicolumn{1}{|c}{ Struktur } & \multicolumn{1}{|c|}{ Judul Berita } \\
\cline { 2 - 3 } & \multicolumn{1}{|c|}{\begin{tabular}{c}
\multicolumn{1}{c|}{ CRS-PT RAPP Bantu Korban Banjir Tiga } \\
Daerah
\end{tabular}} \\
\hline Sintaksis & $\begin{array}{l}\text { Penyajian berita Rakyat Riau ini memberikan } \\
\text { cerminan sikap prihatin dari pihak PT RAPP } \\
\text { dengan transpransi memberikan dan menyalurkan } \\
\text { bantuan kepada korban banjir di tiga kabupaten } \\
\text { diantaranya Kabupaten Kampar, Pelalawan, dan } \\
\text { Kuatan singingi. }\end{array}$ \\
\hline Skrip & $\begin{array}{l}\text { Unsur 5 W+l H telah terpenuhi, tetapi pemilihan } \\
\text { unsur-unsur kelengkapan teks berita di sini } \\
\text { mendukung tema dari Rakyat Riau sendiri. }\end{array}$ \\
\hline
\end{tabular}




\begin{tabular}{|l|l|}
\hline Tematik & $\begin{array}{l}\text { Tematik yang dibangun dalam teks ini kepedulian, } \\
\text { solidaritas, dan bantuan dari pihak PT RAPP } \\
\text { terhadap korban banjir. }\end{array}$ \\
\hline Retoris & $\begin{array}{l}\text { Foto dalam berita ini memberikan gambaran } \\
\text { mengenai Direktur PT RAPP yang sedang } \\
\text { memberikan bantuan. }\end{array}$ \\
\hline
\end{tabular}

\section{Hasil analisis : Framing Rakyat Riau Edisi Rabu, 30 Desember 2009}

\begin{tabular}{|c|c|}
\hline \multirow{2}{*}{$\begin{array}{l}\text { Struktur } \\
\text { Framing }\end{array}$} & Judul Berita \\
\hline & 82 Desa di Kampar Terendam Baniir \\
\hline Sintaksis & $\begin{array}{l}\text { Harian Rakyat Riau megajak pembaca untuk } \\
\text { menjadikan peristiwa baniir menjadi pusat } \\
\text { perhatian. }\end{array}$ \\
\hline Skrip & $\begin{array}{l}\text { Kelengkapan berita dari Harian Rakyat Riau ini } \\
\text { semua sudah lengkap, secara baik. Tetapi } \\
\text { pemilihan dan penggunaan dari kelengkapan ini } \\
\text { belum berimbang dalam banjir di Kampar, } \\
\text { kebijakan pemerintah lebih ditonjolkan dalam } \\
\text { menangani banjir. }\end{array}$ \\
\hline Tematik & $\begin{array}{l}\text { Bingkai dari Rakyat Riau dalam struktur tematis } \\
\text { teks berita ini dibagi dalam } 2 \text { kerangka; (l) } \\
\text { Kebijakan pemerintah sudah tepat hanya perlu } \\
\text { lebih intensif dalam penanganan banjir, (2) } \\
\text { Kerugian sektor ekonomi warga akibat meluapnya } \\
\text { sungai Subayang dan Sungai Tapung di } \\
\text { Kabupaten Kampar. }\end{array}$ \\
\hline Retoris & $\begin{array}{l}\text { Foto dalam berita ini memberikan gambaran } \\
\text { suasana di dalam speedboad milik Tim } \\
\text { penanggulangan bencana kabupaten Kampar. }\end{array}$ \\
\hline
\end{tabular}

Pada pembingkain di harian pagi Rakyat Riau lebih menekankan pada kondisi saat pasca banjir terjadi. Dari tujuh berita tentang banjir ada lima berita yang hanya menceritakan kondisi pasca banjir. Serta cara pembingkaian dengan frame berita pada tinjauan pemerintah dan bantuan dari RAPP. Hal ini menunjukkan bahwa media cetak lokal 
tersebut terbilang belum memberikan pengetahuan mengenai dampak banjir secara jelas.

\section{Peran media massa sebagai saluran dalam proses komunikasi bencana}

Jika dikaitkan dengan tahapan bencana, maka peran media terkait model komunikasi Harold Laswell dapat dilihat pada Gambar 2 berikut. Pada fase 1 (pencegahan), media massa memiliki fungsi sosialisasi dan edukasi untuk membentuk kesiapan masyarakat menghadapi bencana alam. Fungsi sosialisasi dan edukasi ini dibutuhkan pada masa pra bencana. Pada fase 2 (mitigasi, kesiapan, dan peringatan dini) media massa dapat mendukung fungsi pengarahan, kemudian pada fase 3 (tanggap darurat dan bantuan darurat) media massa dapat mendukung fungsi koordinasi dan manajemen yang sangat dibutuhkan untuk koordinasi tim penolong, manajemen distribusi bantuan, koordinasi antar instansi dan manajemen penanganan pengungsi. Pada fase 4 (pemulihan dan rehabilitasi), media massa dapat menjalankan fungsi konseling dan hiburan yang diperlukan saat melakukan rehabilitasi pada korban yang mengalami trauma akibat bencana dan upaya untuk mengembalikan kondisi sosial dan psikologis seperti sediakala. Kemudian pada fase 5 (rekonstruksi), media massa menjadi sarana pembelajaran dan refleksi, serta pengalihan trauma pada proses coping dari warga yang menjadi korban.

Selain itu, berita bencana di media massa harus memperhatikan skala atau besarnya bencana yang terjadi berkaitan dengan nilai berita yang terdapat dalam berita bencana, terkait unsur kemanusiaan, dan elemen prominence. Informasi mengenai hal ini menjadi penting dalam memberitahukan mengenai kemungkinan manajemen bencana dan aktivitas pasca bencana. Informasi mengenai dampak dapat memberikan pemahaman bagi khalayak mengenai kondisi kerusakan, krisis fasilitas, maupun upaya pemulihan yang dapat diupayakan. Dengan kata lain, media massa dapat berperan sebagai "early warning" dalam informasi mengenai bencana yang terjadi.

Komunikasi risiko bencana melalui penyajian berita bencana yang dilakukan media massa sangat penting dalam mendukung edukasi dan 
advokasi masyarakat agar dapat lebih siap dalam menghadapi berbagai permasalahan lingkungan yang terjadi. Pendekatan komunikasi lingkungan dalam penyajian pesan akan membentuk pesan yang lebih mudah dipahami dan memberikan kesadaran pada masyarakat. Pembingkaian realitas dalam pemberitaan bencana alam, juga perlu disajikan dengan data yang baik sehingga upaya komunikasi risiko bencana untuk meminimalisasi kerugian akan tercapai. Ini menunjukkan bahwa peran komunikasi risiko bencana di media massa sangat penting dan dapat menentukan keberhasilan pemerintah untuk memberikan informasi bagi keamanan masyarakat dan mengatasi bencana yang terjadi. 


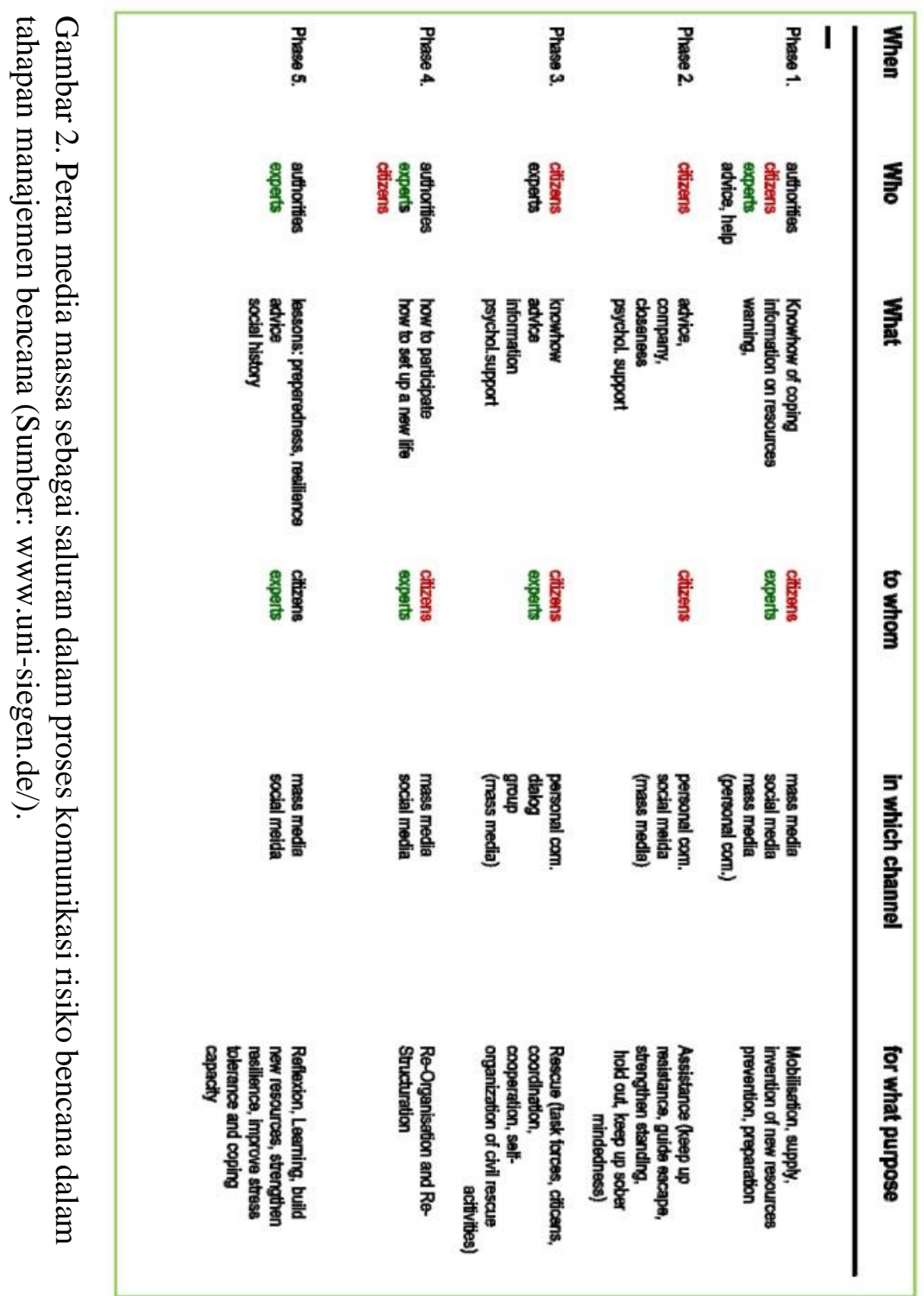




\section{KESIMPULAN}

Pembingkaian (framing) berita bencana pada surat kabar harian pagi Rakyat Riau belum menyajikan pengetahuan mengenai bencana secara detil dan jelas. Frame berita masih menekankan peristiwa bencana pada aktivitas pasca banjir dan aktivitas pemerintah dan pihak filantropi. Fungsi sebagai early warning masih perlu dioptimalkan dan lebih menekankan pada aspek kemanusiaan agar media massa dapat mendukung edukasi kesiapan dan kemampuan masyarakat menghadapi bencana alam.

Berdasarkan kajian ini, disarankan agar para jurnalis media cetak lokal dapat menerapkan pendekatan jurnalisme bencana dengan didasari empati untuk menghasilkan pemberitaan bencana yang tidak merugikan masyarakat. Empati kepada korban bencana diharapkan mampu membangun optimisme hidup korban bencana. Selain itu, jurnalisme warga atau citizen journalism perlu diperhatikan oleh pihak media massa karena dapat menjadi jembatan bagi khalayak untuk mengetahui informasi tanpa batasan dan dukungan pada media komunitas juga diperlukan untuk melengkapi informasi yang dapat diakses masyarakat melalui internet.

\section{DAFTAR PUSTAKA}

Abdillah, Pius dan Prasetya, Danu. 2005. Kamus Lengkap Bahasa Indonesia, Surabaya: ARKOLA.

Cangara, Hafied. 2004. Pengantar llmu Komunikasi, Jakarta: PT Raja Grafindo Persada.

Djuroto, Totok. 2002. Menajemen Penerbitan Pers, Bandung: PT Remaja Rosdakarya.

Effendi, Onong Uchajana. 2004. Ilmun Komunikasi Teori dan Praktek, Bandung: PT Remaja Rosdakarya Offect.

Eryanto. 2004. Analisis Framing Konstruksi, Ideologi dan Politik Media. Yogyakarta: LKIS. 
Herlina Riya. 2008. Analisis Framing Tentang Perbandingan Penyajian Tajuk Rencana Kedatangan Presiden Bush ke Indonesia di Harian Riau Mandiri dan Riau Pos, Pekanbaru : Fakultas Dakwah dan Ilmu Komunikasi UIN SUSKA Riau.

Kusumaninggrat Hihat, dan Punrama. 2005. Jurnalistik Teori dan Praktik, Bandung: PT Remaja Rosdakarya.

Lexy J. Moleong, M.A. 2007. Metodelogi Penelitian Kualitatif. Bandung: PT. Remaja Rosdakarya.

Saparuddin, H.A dan Hmn, Qasyaini. 2003. Tonty Winata dalam Citra Media, Jakarta: JARI.

Siregar, Ashadi dkk. 1996. Bagaimana Meliput dan Menulis Berita Untuk Media Massa, Yogyakarta: Lembaga Penelitian Pendidikan dan Penerbitan.

Sobur, Alex. 2006. Analisis Teks Media: Suatu Pengantar Untuk Analisis Wacana, Analisis Semiotik dan Analisis Framing, Bandung: PT Remaja Rosdakarya.

Suhandang, Kustadi. 2004. Pengantar Jurnalistik: Seputar Organisasi, Produk dan Kode Etik, Bandung: Penerbit Nuansa.

Zaenuddin. 2007. The journalist: Headline (Berita Utama). Jakarta: Prestasi Pustaka. 